Davis, J. M., Wang, Z. \& Janicak, P. G. (1993) A quantitative analysis of clinical orug trials for the treatment of affective disorders. Psychopharmocology Bulletin, 29, $175-181$

Moncrieff, J. (1997) Lithium: evidence reconsidered. British journol of Psychiotry. 171. 113-119.

Wolf, T., Müller-Oertinghausen, B., Ahrens, B., et al (1996) How to interpret findings on mortality of longterm lithium treated manic-depressive patients? Critique of different methodological approaches. Journol of Affective Disorders. 39. 127-132

J.W. Jefferson Dean Foundation for Health, Research and Education. Middleton, Wisconsin 53562, USA

\section{Suicide prevention}

Sir: Lewis et al (1997) provide an interesting contribution towards a strategy for preventing suicide in the general population. Their conclusion, that high-risk strategies will have only a modest effect on population suicide rates, would seem impossible to contradict on the basis of available data. However, their emphasis on prevention in deliberate self-harm patients seems less well founded as no effective preventive measures have yet been documented. They do not refer in detail to other risk factors including depression and other mental disorders. If we assume that the prevalence of depression in the general population is approximately $5 \%$, versus a conservative estimate of $50 \%$ in completed suicides, this would, using the same method as the authors, give a population attributable fraction of approximately 0.3 . Studies generally find that approximately half to two-thirds of mental disorders in patients who consult the general practitioner go undetected. It would therefore seem logical that a possibility for prevention would be through training general practitioners in detecting and treating depression and other mental disorders.

The authors also note that high-risk strategies which focus on post-discharge suicide would be expensive compared with most other medical interventions. However, this would be equally true for services for deliberate self-harm patients or any other high-risk strategy. The only argument that, in financial terms, would justify any intervention aimed at preventing suicide would probably be that there are likely to be other beneficial effects beyond 'merely' saving lives (e.g. improving the quality of life and social trajectory for psychiatric patients).
Lewis, G., Hawton, K. \& Jones, P. (1997) Strategies for preventing suicide. British journol of Psychiatry. 171. $351-354$.

P. B. Mortensen Department of Psychiatric Demography, Psychiatric Hospital in Aarhus. Skovagervej 2, DK-8240 Risskov, Denmark

\section{Suicidal ideation and short-term risk of suicide}

Sir: Morgan \& Stanton (1997) state that $83 \%$ of in-patient suicides report suicidal ideation. Moreover, many of these individuals who proceed to suicide are symptomatically much improved and they suggest this is misleading. Findings from our recent Australian study of 103 in-patient suicides over a four-year period (Shah \& Ganesvaran, 1997) support these findings. In our study, unstable suicidal ideation (i.e. daily fluctuation in suicidal ideation), in contrast to stable suicidal ideation (i.e. continuously either suicidal or not suicidal), was strongly associated with suicide.

Suicidal ideation is not static. Rather, it is a balance between self-destructive and self-preservative wishes at that point in time. Stengel (1977) suggested that victims want neither to live nor to die, but desire both at the same time, usually one more than the other. Some patients, particularly those with recurrent relapses and resistance to treatment, may be perceived by staff as manipulative, provocative, unreasonable, over-dependent and feigning disability; this led to the concept of terminal malignant alienation (Morgan \& Priest, 1991). Patients with fluctuating suicidal ideation are particularly likely to fall into these categories. This results in staff criticism and a lower level of support, leading to alienation. The combination of fluctuating suicidal ideation and alienation can lead to failure in the recognition of seriousness of suicide risk. Moreover, this may lead to observation complacency and absconding or less scrutiny while granting leave. In our Australian series $36 \%$ committed suicide after absconding and $35 \%$ while on approved leave.

Morgan, H. G. \& Priest, P. (199I) Suicide and other unexpected deaths among psychiatric in-patients. The Bristol confidential inquiry. British journal of Psychiotry. 158. 368-374.

- Stanton, R. (1997) Suicide among psychiatric inpatients in a changing clinical scene. Suicidal ideation as a paramount index of short-term risk. British journol of Psychiotry, 171, 561-563.
Shah, A. K. \& Ganesvaran, T. (1997) Inpatient suicides in an Australian mental hospital. Austrolio ond New Zeolond journal of Psychiotry. 31. 291-298

Stengel, E. (1977) Suicide and Attempted Surcide. Ringwood. Victoria: Penguin.

A. Shah West Middlesex University Hospital, Twickenham Road, Isleworth, Middlesex TW7 6AF

\section{Minor psychiatric morbidity in NHS workers}

Sir: While the extensive survey by Wall et al (1997) covered many NHS workers and appears to have validated many of the smaller-scale studies, the sampling methods used will have excluded many of those at highest risk of work-related psychiatric morbidity. The exclusion of staff "not in a position to respond" includes those on sickness absence and those who have moved because of staff turnover. Both increased rates of sickness absence and high staff turnover can be used as indicators of occupational stress within an organisation (Cooper, 1996). Exclusion of staff redeployed within trusts excludes those who have been moved because of stress-related disorders and ignores the fact that changes in role and responsibility can be major stressors in their own right. Gathering further information about these groups would help to overcome these methodological problems.

Finally, the clinical implications drawn from the study focus on tertiary level interventions, provided through occupational health departments, rather than the primary and secondary level interventions (mental health promotion and mental illness prevention) recommended in the $A B C$ of Mental Health in the Workplace (HMSO, 1996).

Cooper, C. (1996) Stress in the workplace. British Journol of Hospital Medicine, 55, 559-563.

HMSO (1996) $A B C$ of Mentol Health in the Workplace: $A$ Resource Pock for Employers. London: HMSO.

Wall, T. D., Bolden, R. I., Borrill, C. S., *t al (1997) Minor psychiatric disorder in NHS trust staff: occupational and gender differences. British fournal of Psychiatry. 17I. 519-524

M. White Section of Community Psychiatry, Department of Mental Health Sciences, St George's Hospital Medical Schoo, Jenner Wing, Cranmer Terrace, London SWI7 ORE 